\title{
Évelyne Grossman, La défiguration. Artaud - Beckett - Michaux
}

alessandro giarda

\section{(2) OpenEdition}

1 Journals

\section{Edizione digitale}

URL: https://journals.openedition.org/studifrancesi/46259

DOI: 10.4000/studifrancesi.46259

ISSN: 2421-5856

\section{Editore}

Rosenberg \& Sellier

\section{Edizione cartacea}

Data di pubblicazione: 1 octobre 2007

Paginazione: 476

ISSN: 0039-2944

\section{Notizia bibliografica digitale}

alessandro giarda, «Évelyne Grossman, La défiguration. Artaud - Beckett - Michaux», Studi Francesi

[Online], 152 (LI | II) | 2007, online dal 30 novembre 2015, consultato il 24 novembre 2021. URL: http:// journals.openedition.org/studifrancesi/46259; DOI: https://doi.org/10.4000/studifrancesi.46259

Questo documento è stato generato automaticamente il 24 novembre 2021.

\section{(c) (i) (9)}

Studi Francesi è distribuita con Licenza Creative Commons Attribuzione - Non commerciale - Non opere derivate 4.0 Internazionale. 


\title{
Évelyne Grossman, La défiguration. Artaud - Beckett - Michaux
}

\author{
alessandro giarda
}

\section{NOTIZIA}

ÉVELYNE GROSSMAN, La défiguration. Artaud - Beckett - Michaux, Paris, Les Editions de Minuit, 2004, pp. 116.

1 Sotto l'espressione défiguration Évelyne Grossman individua una poetica che, a partire dai primi decenni del xx secolo, attraversa incessantemente gran parte della produzione artistica e letteraria contemporanea. La pratica della défiguration, nella tesi qui esposta, nasce come reazione alla normopatia, alla malattia della forma che contagia gran parte degli aspetti dell'esistenza dei nostri giorni, al formalismo (leggi anche conformismo) che riconduce una realtà molteplice nei ranghi di una rappresentazione forzatamente univoca. La défiguration mette dunque in discussione l'ideologia della società dell'immagine; essa deforma, disfa, demistifica, decostruisce le figure ricevute in eredità dall'arte, dalla scrittura, dal senso, dalla storia, «sconvolge i nostri sistemi di pensiero e la tranquilla stabilità delle opposizioni che sovente lo governano» (p. 113). Sorta di "nouvel iconoclame", la défiguration non costituisce tuttavia soltanto un atto di violenza negativa puramente distruttrice, è piuttosto una forza di creazione che stravolge le forme stratificate del senso e le rianima rimettendole in movimento, rendendole «sempiterne» ossia proiettandole in una dimensione di continuo divenire altro da sé.

2 Artaud, Beckett e Michaux sono tra coloro che alla pari di altri autori quali Céline, Leiris, Cioran, Blanchot, con la loro scrittura hanno fornito la testimonianza più acuta di questa tendenza. Come sottolinea l'autrice del saggio questi scrittori «n'en finissent pas d'inventer une forme, un style qui figure-défigure l'informe, une écriture dont l'incessant mouvement ne fixe pas mais maintienne ouverte l'oscillation: ressassement chez certains, jeux infinis d'une négativité en mouvement pour d'autres, force d'une 
langue en suspens d'une forme à l'autre» (p. 114). La pratica della défiguration si evidenzia nei loro testi attraverso lo scollamento subito dalle immagini e dai corpi (interessante a questo proposito il parallelo tra Artaud e la pittura di Balthus), attraverso l'ambiguità e la doppiezza dei corpi (Être pèresmères), la loro instabilità e la loro capacità di metamorfosi (vedi le Meidosems di Michaux), nonché nell'attitudine dei soggetti ad abbandonare un'identità fissa a favore di una pluralità di identità in movimento: des identités, primo passo verso una più radicale désidentité. Ma la défiguration non risparmia nemmeno la lingua: è essa a far sì che gli scritti di Artaud, Beckett e Michaux appaiano come «textes troués», aperti, senza contorni né definizione. La Grossman parla a tal proposito di lingua senza stile (Mal vu mal dit, giocando con il titolo di un'opera di Beckett), di «écriture insectueuse» che si tradisce, si cancella e rinasce, inventando senza riposo un ritmo che impedisce al senso di rapprendersi, di fissarsi in forma, in figura (di stile, di retorica).

Le conclusioni della Grossman sono difficilmente confutabili: «L'écriture moderne s'invente dans cet écart [... ] entre l'amour de la forme, langue et la fascination d'une hémorragie sans fin du sens et des mots» (p. 114). 